\title{
Characterisation of sucking dynamics of breastfeeding preterm infants: a cross sectional study
}

\author{
Donna T. Geddes ${ }^{1 *}$, Kok Chooi ${ }^{2,3}$, Kathryn Nancarrow ${ }^{2,3}$, Anna R. Hepworth ${ }^{1}$, Hazel Gardner ${ }^{1}$ and Karen Simmer ${ }^{2,3}$
}

\begin{abstract}
Background: Full breastfeeding is the ultimate aim for preterm infants to ensure they receive the full benefits of human milk however, preterm infants face a number of challenges associated with their immaturity and associated morbidities. In order to facilitate oral feeding, it is essential to have a sound knowledge of the sucking dynamics of the breastfed infant. The aim of this study was to measure and describe the sucking dynamics of the preterm breastfeeding infant.

Methods: A prospective cross sectional observational study was carried out at King Edward Memorial Hospital, Perth. 38 mothers and their preterm infants (birth gestation age: 23.6-33.3 weeks; corrected gestation age 32.7 to 39.9 weeks) were recruited. Intra-oral vacuum levels, tongue movement and milk intake for a single breastfeed was measured. Statistical analysis employed linear regression and linear mixed effects models.

Results: Synchronised ultrasound and intra-oral vacuum measurements show that the preterm infant generates vacuum by lowering their tongue in a parallel fashion, without distortion of the nipple/nipple shield. Baseline (B), mean (M) and (P) peak suck burst vacuums weakened over the course of a feed (B: $p=0.015 ; \mathrm{M}: p=0.018 ; \mathrm{P}: p=0.044$ ) and mean and peak vacuums were weaker if the mother fed with a nipple shield (M: $p=0.012 ; P: p=0.021$ ). Infant milk intakes were higher when infants sucked for longer $(p=0.002)$, sucked for a greater proportion of the feed $(p=0.002)$, or had a greater sucking efficiency $(p<0.001)$.

Conclusions: Breastfeeding preterm infants generated intra-oral vacuum in the same manner as term infants. Nipple shields were associated with weaker intra-oral vacuums. However, vacuum strengths were not associated with milk intake rather time spent actively sucking was related to milk volumes. Further research is required to elucidate factors that influence preterm infant milk intake during breastfeeding.
\end{abstract}

Keywords: Breastfeeding, Preterm, Infant feeding, Lactation, Premature, Infant

\section{Background}

Breastfeeding provides advantages for both the mother and infant [1-5] that cannot be replicated by either artificial milks or artificial feeding methods [6]. Human milk itself, confers passive immunity to the infant, protecting against infection [7], which is highly advantageous to the immature preterm infant. Human milk also plays a role in the colonization of the preterm infants gut $[8,9]$, by providing beneficial bacteria [10], along

\footnotetext{
* Correspondence: donna.geddes@uwa.edu.au

${ }^{1}$ School of Molecular Sciences, Faculty of Science M310, The University of Western Australia, Perth, WA 6009, Australia

Full list of author information is available at the end of the article
}

with milk components such as human milk oligosaccharides (HMOs) that disrupt mechanisms leading to necrotizing enterocolitis (NEC) [11] through influencing bacterial growth [12]. Further, the incidence of NEC is six times higher in formula-fed infants compared to human milk fed infants $[13,14]$.

Whilst the ultimate nutritional goal is to achieve full breastfeeding in preterm infants, many variables influence the establishment and continuation of lactation, including nutritional $[15,16]$, biological $[17,18]$, psychological [19], cultural [20,21] and social [22] components, all of which are vastly different for the mother/ pre-term infant dyad compared to the mother/term 
infant dyad. Further, the establishment of breastfeeding is fraught with problems associated with the immaturity and health of the preterm infant [23]. Often the preterm infant is too ill to breastfeed immediately, and is tubefed while oral feeding is established. During this time the initiation and establishment of a maternal milk supply is a priority [24]. Achieving and maintaining a plentiful milk supply is hampered by a tendency for the initiation of lactation to be delayed and less milk to be expressed compared to mothers of term infants $[25,26]$. Recent evidence has suggested that expressing milk within an hour of delivery has a significant impact on milk volumes produced at 6 weeks post partum [27]. However, there is also a strong relationship between the frequency of pumping and milk volume [28, 29].

Indeed for breastfeeding to be successful, adequate amounts of milk must be removed frequently from the breast to ensure continued milk synthesis [30,31]. While term infants receive 500 to $1000 \mathrm{~mL} /$ day [32], pumping studies show that milk production in the preterm mother tends to be maintained at around 340 to $640 \mathrm{~mL} /$ day [33, 34]. Similar to pumping studies [35], recent ultrasound studies of breastfeeding term infants, indicate that vacuum is instrumental in milk removal $[36,37]$ and this is commensurate with preterm bottlefed infants, where it has been shown that the development of vacuum strength and rhythmicity over time is necessary to improve the feed effectiveness and efficiency $[38,39]$. Furthermore, adequate coordination of sucking, swallowing and breathing [40-43] is essential for safe feeding and due to neurological and developmental immaturity; coordination of sucking, swallowing and breathing may be compromised and then further compounded by respiratory conditions.

Few objective studies have been carried out to investigate the mechanisms of breastfeeding in the preterm infant, often presumed to be different or 'immature' compared to term infants. This belief has been based on clinical observation and measurement of intra-oral vacuums, but no studies have imaged the sucking mechanism of breastfed preterm infants yet this is essential, to devise successful strategies focused on facilitating full breastfeeding. Recent ultrasound studies of term breastfeeding infants confirm that term breastfeed infants employ a parallel movement of the anterior and mid tongue to remove milk from the breast and use a more wave like motion of the posterior tongue to clear the milk bolus from the oral cavity during the oral phase of swallowing [44-46].

\section{Methods}

The aims of this study were to measure and describe the sucking dynamics of the preterm breastfeeding infant feeding with a nipple shield (tongue movement and intraoral vacuum) and explore relationships with milk intake.

\section{Participants}

A convenience sample of 47 mothers and infants (birth gestation age: 23.6-33.3 weeks; corrected gestation age (CGA) 32.7 to 39.9 weeks) was recruited from the special care nurseries of King Edward Memorial Hospital for Women (KEMH), Perth between 1 August 2011 and 30 June 2012. Five infants were discharged before a feed could be monitored and 4 were excluded due to technical issues recording intra-oral vacuum and ultrasound images, leaving a sample size of 38 . These mothers were a subset of a larger cohort taking part in a randomized controlled trial to assess the efficacy of a novel feeding system (AustralianNewZealandClinicalTrialsRegistry, ACTRN12614000875606, http://www.ANZCTR.org.au/ ACTRN12614000875606.aspx). The infants recruited to the study were healthy preterm infants admitted to the NICU, whose mothers intended to breastfeed. Nipple shields are used to facilitate the establishment of breastfeeding particularly in infants having difficulty maintaining attachment to the breast. Exclusion criteria included oro-facial anomalies that might affect feeding, as well as intraventricular hemorrhage and other congenital anomalies. All infants were required to be successfully latching and sucking at the breast before participating in the study. Mothers supplied written, informed consent to participate in the study, which was approved by the Scientific Research Ethics Committee of King Edward Memorial Hospital. One breastfeed was monitored for each infant.

\section{Infant milk intake}

Milk intake was determined by test weights taken immediately before and after the breastfeed [32] (Baby Weigh Scale, Medela AG, Baar, Switzerland). The difference in weight $(\mathrm{g})$ was equivalent to the transfer volume $(\mathrm{mL})$. Milk transfer rate $(\mathrm{mL} / \mathrm{min})$ was calculated by dividing the volume of milk $(\mathrm{mL})$ consumed by the duration of the feed (minutes). Intra-oral vacuum was measured using the methods previously described by Geddes et al., 2008 [36].

\section{Ultrasound imaging}

Submental ultrasound scans of the midline of the infant's oral cavity were acquired [47-49] using a portable TITAN ultrasound system, with an endocavity convex transducer ICT $8-5 \mathrm{MHz}$ (SonoSite Inc.). Details regarding this technique have been described in detail previously [36]. Signals from the ultrasound machine and pressure transducer were recorded simultaneously with a Video Capture Module (ADInstruments). This module allows synchronized recording and playback of a movie file and LabChart data, allowing analysis of the tongue 
movement in relation to the vacuum cycle. Recording of the data was begun prior to the infant latching to the breast and ceased at the end of the feed.

The first three well-visualized nutritive suck cycles were selected from each feed. Tongue and nipple movement were measured on two still images from each suck cycle when the mid tongue was at its highest (TU) and lowest points (TD) using Screen Calipers v 3.2 (Iconico Inc.). Measurements made were: nipple to hard-soft palate junction (N-HSPJ), intra-oral depth (IOD; vertical measurement of the mid tongue lowering creating the space accommodating the milk bolus), and nipple diameter at 2, 5, 10, 15 and $20 \mathrm{~mm}$ from the tip of the nipple.

\section{Measurement of infant intra-oral pressure}

Infant intraoral pressures were measured via a small silastic tube filled with sterile water and taped alongside the nipple and attached to a disposable pressure transducer (Cobe Laboratories, Frenchs Forest, NSW, Australia). The transducer was connected to an amp bridge (ADInstruments, Castle Hill, NSW, Australia) and the output was recorded using MacLab (ADInstruments) and software package Chart v5.0.2 (ADInstruments) on a laptop computer (Mac OS X v10.3.8).

Suck burst measurements made were: mean minimum pressure (peak vacuum) and mean maximum pressure (baseline vacuum), mean pressure, suck rate and duration of the suck burst. Mean pressure and pause duration were measured for the pauses between the suck bursts.

\section{Statistical analysis}

Analyses were performed using R 3.0.3 for Mac OS X [50]. Packages nlme [51] and lattice [52] were used for linear mixed effects models and graphical exploration, respectively. Differences were considered significant when $p<0.05$. Descriptive statistics are presented as mean \pm sd (range) and/or median [IQR] otherwise. Parameter estimates are presented as estimate [95\% confidence interval $(\mathrm{CI})]$ and included where relevant due to transformation of some of the variables.

Welch two sample $t$-tests were used to test for differences between infants who had and had not achieved full suck feeds and between infants fed with and without a nipple shield. Linear regression was used to test for univariate associations between milk intake (square root transform) and feed characteristics (prescribed volume, average vacuum across the feed, feed duration, time pausing, number of suck bursts, number of single sucks, percentage of single sucks).

All other variables: NHSPJ, IOD, nipple diameter, measurement location (nipple diameter), time elapsed since beginning of feed; mean, baseline and peak vacuums; burst duration; sucking rate; use of nipple shield during the feed, current weight, CGA, postnatal age, birth gestational age and weight, age at introduction of suck feeds and achievement of full suck feeds, and the timing of the monitored feeds were analysed using linear mixed effects models to account for the related nature of the data. Data was grouped by infant, with alternate grouping of tongue position within infant considered for all tongue movement variables. Significant effects of tongue position were considered to indicate individual differences in degree of movement. A simultaneous linear regression model approach was used to investigate frequency of significant patterns within infants and whether these patterns were consistent.

Tongue movement, vacuum, and sucking patterns data were analysed as with linear mixed effects models. Random effects considered were random intercepts, and in models with time based variables, individual time patterns. Random effects were only included if the term was also included in the fixed effects. Suitability of random effects was tested using likelihood ratio tests. Random effects other than random intercepts were considered to indicate different patterns between groupings.

Analysis specific fixed effects related to the research question included measures that changed for example when the tongue was either up or down and included tongue position (NHSPJ, IOD, nipple diameter), measurement location (nipple diameter), time elapsed since beginning of feed, either as linear or 2nd order polynomial (mean, baseline and peak vacuums; burst duration; sucking rate). Covariates of interest that were considered to potentially affect the relationship/s between the response variable/s and the fixed effects were use of nipple shield during the feed, current weight, CGA, postnatal age, birth gestational age and weight, age at introduction of suck feeds and achievement of full suck feeds, and the timing of the monitored feeds relative to these last two. Final models were selected using stepwise modeling, omitting covariates with marginal significance $<0.05$, starting with analysis specific fixed effects. Fixed effects were tested by considering the set of models that included one additional covariate, interaction, or higher order term; this was considered to be the final model when only terms that were considered to be significant as fixed or random effects were retained. Appropriateness of model fits were assessed visually from standard residual plots.

Sucking rate was analysed as per vacuum variables. Measurements of $>200$ sucks per minute were omitted ( $n=9$, leaving $n=1681$ records for analysis) as these are artifacts of the measurement process. Number of sucks per burst was grouped as 'single' ( 1 suck), $<10$ sucks and $10+$ sucks. Linear mixed effects models with absolute max or absolute min vacuum as response and suck burst category as the fixed effect were used to assess how vacuum and number of sucks related; Tukey's all pair 
comparisons was used to determine which suck burst categories were different. No covariates were considered.

\section{Results \\ Participants}

Infant (22 female, 16 male) characteristics are shown in Table 1. Missing data for the 38 infants analysed include: weight at the study session $(n=1)$, milk intake and sucking efficiency $(n=3)$; tongue movement data could not be measured due to technical errors in video recording for 9 infants.

Eight infants had achieved full suck feeds and all but 6 infants were fed using a nipple shield. Infants that had reached full suck feeds were older (CGA; $p=0.003$ ) and use of a nipple shield was not associated with CGA $(p=0.34)$.

\section{Feed characteristics}

Feed characteristics are detailed in Table 2. Three infants had no measurable milk intake $(0 \mathrm{~mL})$ and 7 had milk intakes of $4 \mathrm{~mL}$ or less. Milk intakes were higher when infants sucked for a longer time $(p=0.002)$, spent a greater proportion of the feed sucking $(p=0.002)$, or had a greater sucking efficiency $(p<0.001)$. Effect sizes were small (estimate [95\% CI]: additional $0.07[0.01-0.18] \mathrm{mL}$ for each additional minute sucking; $0.06[0.01,0.16] \mathrm{mL}$ for each additional $5 \%$ of feed spent sucking; 0.07 [0.02, 0.15] $\mathrm{mL}$ for each additional $\mathrm{ml} / \mathrm{min}$ efficiency) reflecting the

Table 1 Infant characteristics of preterm infants monitored for a single breastfeed

\begin{tabular}{|c|c|c|c|}
\hline & Mean \pm SD & Median [IQR] & Range \\
\hline \multicolumn{4}{|l|}{ Birth } \\
\hline age (weeks) & $29.9 \pm 2.8$ & $\begin{array}{l}30.6 \\
{[28.1,32.1]}\end{array}$ & $23.6-33.6$ \\
\hline weight (g) & $1364 \pm 432$ & $\begin{array}{l}1358 \\
{[1085,1716]}\end{array}$ & $540-2080$ \\
\hline \multicolumn{4}{|l|}{ Current } \\
\hline age (CGA, weeks) & $35.8 \pm 1.6$ & & $32.7-39.9$ \\
\hline age (post natal, weeks) & $5.9 \pm 3.8$ & $5.2[3.4,7.4]$ & $1.0-16.3$ \\
\hline weight (g) & $2118 \pm 385$ & & $1430-3220$ \\
\hline \multicolumn{4}{|l|}{ Suck feeds } \\
\hline Introduced (CGA, weeks) & $33.4 \pm 0.8$ & $\begin{array}{l}33.3 \\
{[32.9,33.9]}\end{array}$ & $31.4-35.3$ \\
\hline Introduced (post natal, weeks) & $3.4 \pm 2.7$ & $2.8[1.3,4.9]$ & $0.4-10.6$ \\
\hline Full sucks (CGA, weeks) & $36.8 \pm 1.2$ & $\begin{array}{l}36.7 \\
{[36.0,37.3]}\end{array}$ & $34.9-40.1$ \\
\hline Full sucks (post natal, weeks) & $6.9 \pm 3.6$ & $6.0[4.2,8.7]$ & $2.4-16.6$ \\
\hline \multicolumn{4}{|l|}{ Study day } \\
\hline weeks since first suck & $2.4 \pm 1.6$ & $2.1[1.2,3.7]$ & $0-5.7$ \\
\hline weeks since full sucks ${ }^{a}$ & $-1.0 \pm 1.2$ & $\begin{array}{l}-1.0 \\
{[-1.7,-0.3]}\end{array}$ & $-3.9-1.1$ \\
\hline
\end{tabular}

${ }^{a}$ Weeks since full sucks: negative values indicate the infant was monitored $x$ weeks prior to full suck feeds achieved
Table 2 Feed characteristics of infants during a monitored breastfeed (ultrasound imaging and measurement of intra-oral pressure)

\begin{tabular}{|c|c|c|c|}
\hline & Mean \pm SD & Median [IQR] & Range \\
\hline Feed duration (min) & $13.8 \pm 7.3$ & $\begin{array}{l}11.4(8.3 \\
18.1)\end{array}$ & $2.4-28.6$ \\
\hline Sucking duration (min) & $5.0 \pm 3.6$ & $3.3(2.2,7.4)$ & $1.6-11.9$ \\
\hline $\begin{array}{l}\text { Proportion (\%) of feed } \\
\text { sucking }\end{array}$ & $38 \pm 18$ & $34(24,49)$ & $10-86$ \\
\hline \multicolumn{4}{|l|}{ Suck bursts } \\
\hline Total & $50.7 \pm 34.7$ & $39(28,64)$ & $6-133$ \\
\hline single sucks & $6.2 \pm 4.7$ & $5(3,9.5)$ & $0-18$ \\
\hline$\%$ single sucks & $13 \pm 10$ & $11(6,17)$ & $0-38$ \\
\hline Mean Vacuum (mmHg) & $-40.6 \pm 27.8$ & $\begin{array}{l}-33.0 \\
(-46.6,-22.4)\end{array}$ & $-126.4--0.4$ \\
\hline Milk intake (mL) & $14.4 \pm 13.4$ & $12(4,21)$ & $0-60$ \\
\hline Prescribed volumes (mL) & $45 \pm 8$ & $45(40,50)$ & $30-60$ \\
\hline $\begin{array}{l}\text { Sucking efficiency } \\
(\mathrm{mL} / \mathrm{min})^{*}\end{array}$ & $3.7 \pm 4.1$ & $2.3(1.2,4.4)$ & $0-19.8$ \\
\hline
\end{tabular}

typically small milk intakes and the large variation in sucking durations, feed proportions, and efficiency. No associations were seen with other considered covariates.

\section{Characteristics of tongue movement}

Synchronised ultrasound and intra-oral vacuum measurements show, that as the infant tongue is lowered a vacuum (decreased negative pressure) is generated and the as the tongue is raised the vacuum decreases in strength (increased negative pressure) (Figs. 1 and 2). Ultrasound measurements of N-HSPJ, intra-oral depth and nipple diameters are given in Table 3 . There were baseline differences between infants on all measures $(p<0.001$ all cases). The average difference between tongue up and tongue down differs between individuals for intra-oral depth (IOD; $1.9-8.8 \mathrm{~mm} ; p<0.001$ ) and nipple diameters $(1.9-8.8 \mathrm{~mm} ; 2 \mathrm{~mm}:-0.8,4.2 ; 5 \mathrm{~mm}$ : $-0.7-3.9 ; 10:-1.2-3.1 ; 15:-0.5-2 . ; \mathrm{p}<0.001$; Fig. 3) but not for N-HSPJ distance $(p=0.47)$. For all infants IOD was significantly different for tongue up and tongue down $(p<0.003)$. Tongue up measurements are expected to be zero (tongue in apposition with the palate), 3 infants had average measures significantly different from zero $(p<0.026)$. For nipple diameters 3 infants showed different amounts of movement at different locations and there were 7 infants with no significant difference and no evidence of association with nipple shield use $(p=0.61)$.

When a nipple shield was used, N-HSPJ distances were on average $2.4 \mathrm{~mm}$ [95\% CI: $0.5,4.3]$ longer $(p=0.017)$, and nipple diameters were on average $3.9 \mathrm{~mm}$ (95\% CI: $2.2,5.6)$ larger than without a nipple shield. There was no association between nipple shield use and IOD $(p=0.21$; 


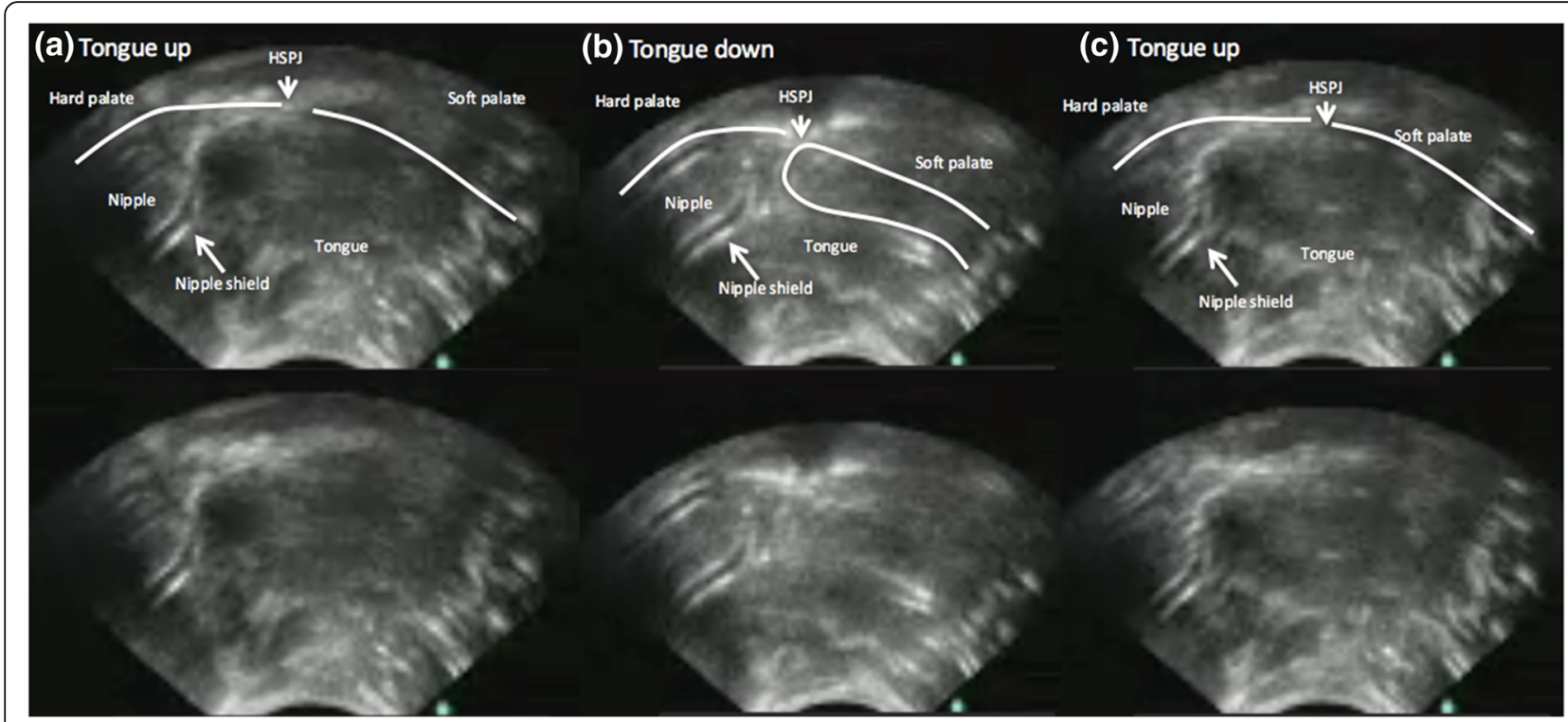

Fig. 1 Ultrasound images of one cycle of a preterm breastfeeding infant feeding with a nipple shield (a) tongue up corresponds with baseline vacuum (b) when the tongue is lowered to the lowest point peak vacuum is applied to the breast and milk flows (c) tongue returns to the soft palate and milk is removed from the oral cavity

mean: $0.5 \mathrm{~mm}$; 95\% CI: -0.3, 1.3). No significant interactions were seen between shield use and either tongue up or tongue down (N-HSPJ, $p=0.28$; nipple diameters, $p=0.074$ ) or location (nipple diameters, $p=0.11$ ).

There were no significant associations with any of the other considered covariates, after accounting for tongue position, use of nipple shield, and in the case of nipple diameters, location of measurement.

\section{Intra-oral vacuum}

Suck bursts were shorter than pauses $(p<0.001)$. Pause durations were univariately associated with age relative to full suck feeds $(p=0.019)$, but this association did not remain if any one of birth weight, postnatal age, age at introduction of suck feeds, or nipple shield use was accounted for. Suck burst durations were not associated with any of the considered covariates $(p>0.19)$.

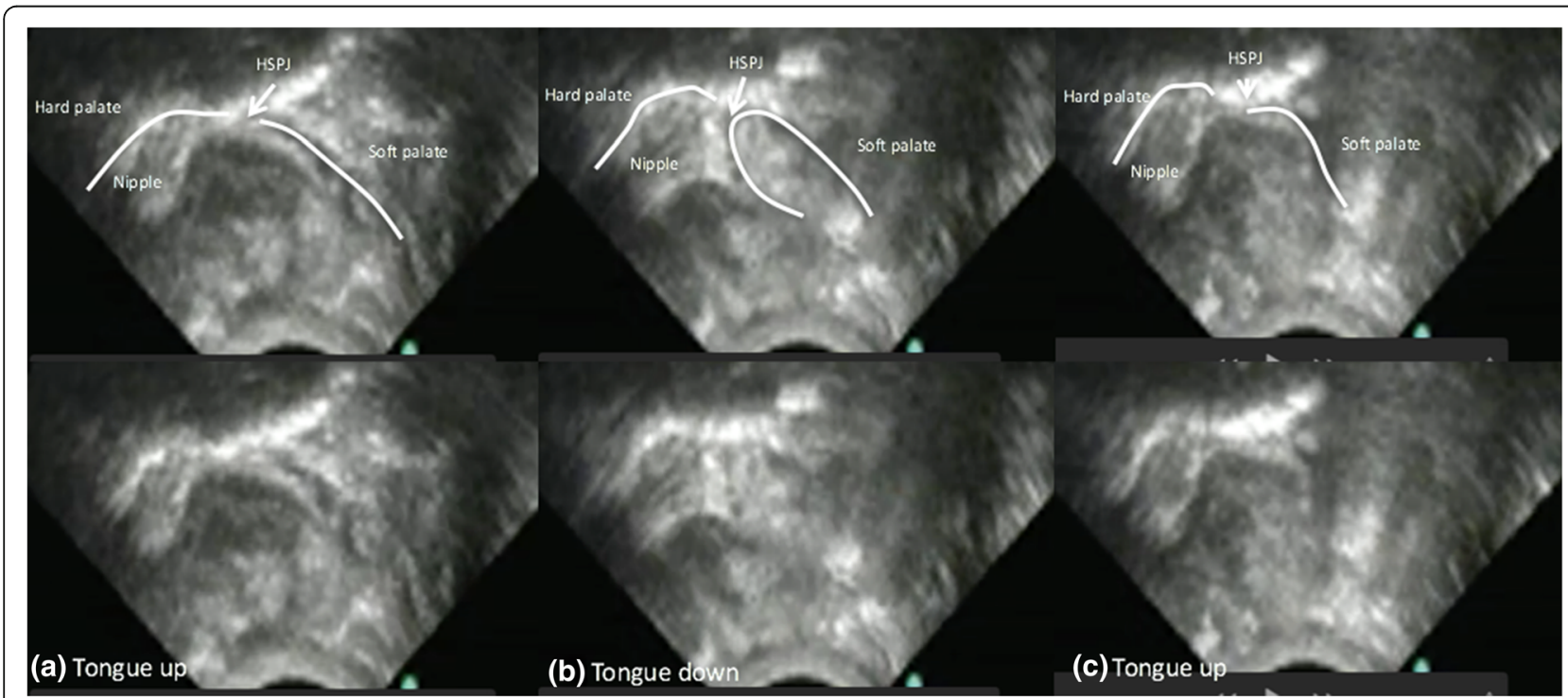

Fig. 2 Ultrasound images of one cycle of a preterm breastfeeding infant (a) tongue up corresponds with baseline vacuum (b) when the tongue is lowered to the lowest point peak vacuum is applied to the breast and milk flows (c) tongue returns to the soft palate and milk is removed from the oral cavity 
Table 3 Tongue movement measurements at tongue up and tongue down (mean \pm SD), for all infants and suck cycles. Nipple diameters are measured at 2, 5, 10, and $15 \mathrm{~mm}$ from the tip of the nipple and are separated by whether the feed was given with or without a nipple shield. *Nipple diameters are missing at tongue up for one infant; $15 \mathrm{~mm}$ location was not measurable on 12 tongue down and 14 tongue up images

\begin{tabular}{|c|c|c|c|c|c|c|}
\hline & \multicolumn{2}{|c|}{ With nipple shield $\left(n=67^{\mathrm{a}}\right)$} & \multicolumn{2}{|c|}{ Without nipple shield $(n=18)$} & \multicolumn{2}{|c|}{ Combined data } \\
\hline & Tongue up & Tongue down & Tongue up & Tongue down & Tongue up & Tongue down \\
\hline N-HSPJ distance $(\mathrm{mm})$ & $7.0 \pm 2.5$ & $5.3 \pm 2.2$ & $4.8 \pm 1.2$ & $2.7 \pm 1.0$ & $6.5 \pm 2.5$ & $4.7 \pm 2.3$ \\
\hline Intra-oral depth (mm) & $0.3 \pm 0.5$ & $4.3 \pm 1.9$ & $0.2 \pm 0.6$ & $3.4 \pm 1.2$ & $0.3 \pm 0.5^{*}$ & $4.1 \pm 1.8$ \\
\hline \multicolumn{7}{|l|}{ Nipple diameters (mm) } \\
\hline $2 \mathrm{~mm}$ & $10.0 \pm 2.2$ & $11.3 \pm 2.1$ & $5.5 \pm 1.2$ & $7.9 \pm 1.0$ & $9.1 \pm 2.8$ & $10.6 \pm 2.4$ \\
\hline $5 \mathrm{~mm}$ & $11.4 \pm 2.2$ & $12.6 \pm 2.1$ & $7.3 \pm 1.3$ & $9.1 \pm 1.4$ & $10.6 \pm 2.7$ & $11.9 \pm 2.5$ \\
\hline $10 \mathrm{~mm}$ & $12.0 \pm 2.3$ & $13.0 \pm 2.1$ & $8.0 \pm 1.4$ & $9.7 \pm 1.3$ & $11.2 \pm 2.7$ & $12.3 \pm 2.4$ \\
\hline $15 \mathrm{~mm}$ & $12.8 \pm 2.2$ & $13.6 \pm 2.1$ & $8.8 \pm 1.1$ & $9.8 \pm 1.4$ & $12.0 \pm 2.6$ & $12.9 \pm 2.5$ \\
\hline
\end{tabular}

${ }^{\mathrm{a}} \mathrm{OOD}$ at tongue up is highly skewed: median $[\mathrm{IQR}]=0[0,0.5]$

The variability of baseline vacuum and mean vacuum do not differ significantly $(P=0.062)$. Peak vacuum is significantly $(p<0.001)$ more variable than both baseline and mean vacuum (Fig. 4). Mean suck burst vacuums weakened over the course of a feed (Fig. $1 ; p=0.018$ ), and were weaker with a nipple shield (Fig. $1 ; p=0.012$ ) or if the infant had not achieved full suck feeds $(p=0.043)$. Pause vacuums also weakened over the course of a feed $(p<0.001)$.
Baseline suck burst vacuums weakened across the course of a feed (Fig. $4 ; p=0.015$ ) with no other associations seen $(p>0.17)$. Peak suck burst vacuums also weakened across the course of the feed (Fig. $4 ; p=0.044$ ), and were weaker when the infant was fed using a nipple shield $(p=0.021)$, and in infants who had not achieved full suck feeds $(p=0.004)$. For all measures, there were significantly different patterns between infants (Fig. 5; $p<0.001)$. No robust associations were seen with

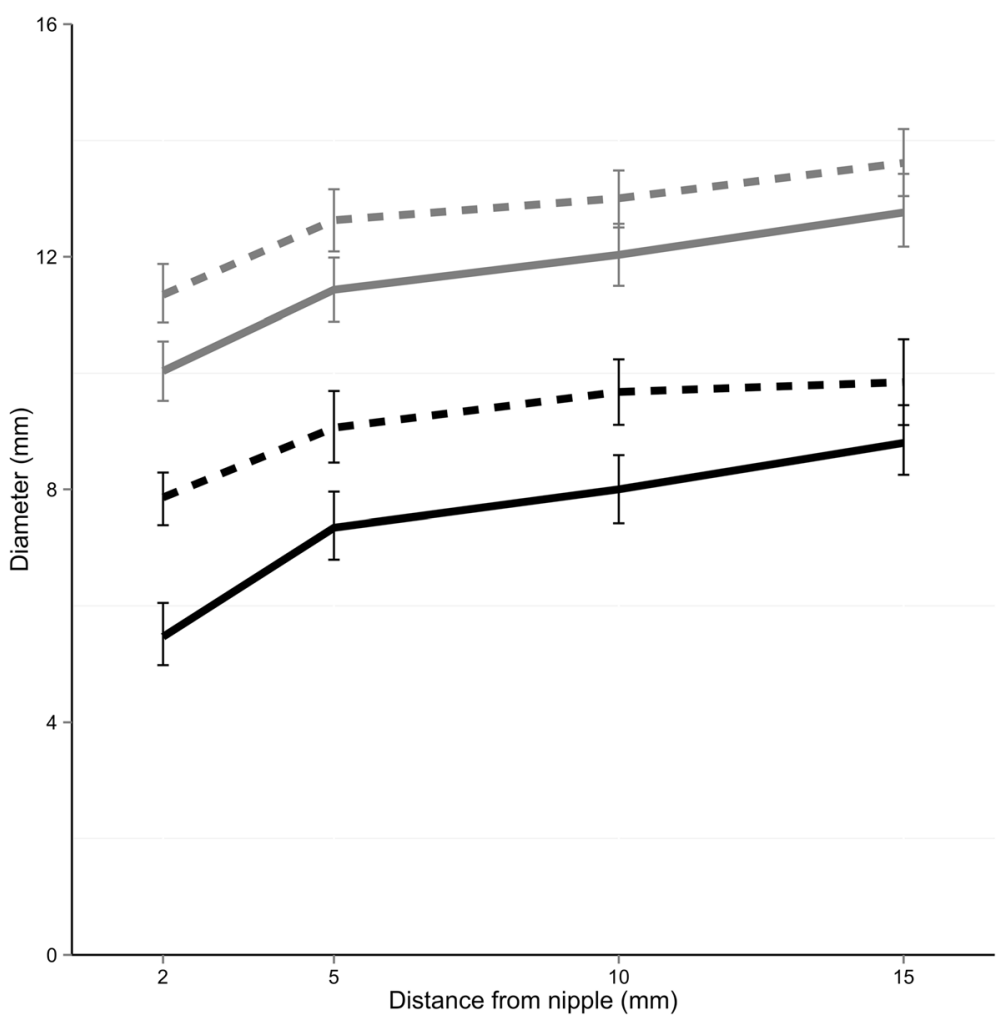

Fig. 3 Nipple diameters plotted at different positions of the nipple $(2,5,10$ and $15 \mathrm{~mm}$ ) for the breastfeeds with a nipple shield (grey lines; $n=32)$ and without a shield black lines; $n=6$ ). Continuous lines represent nipple diameter when the tongue is up and dotted lines when the tongue is down 


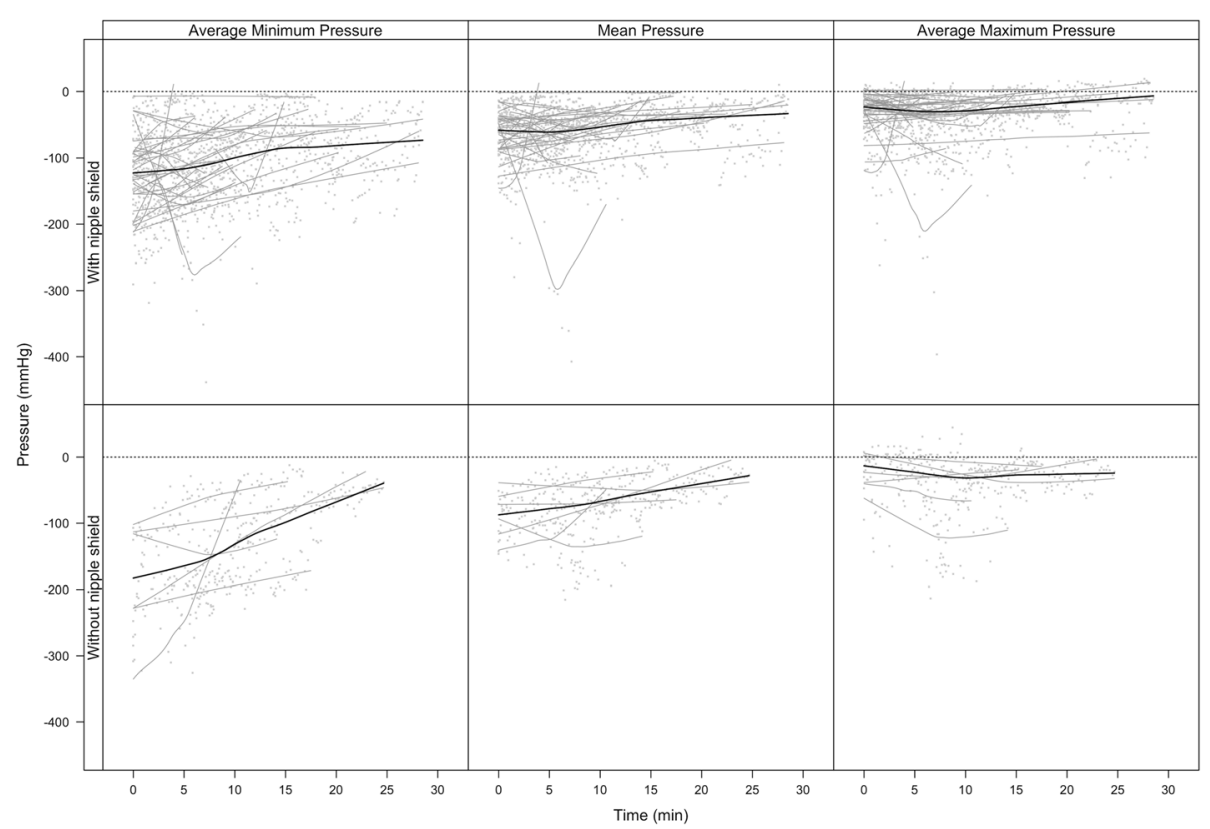

Fig. 4 Average minimum (peak vacuum), mean and average maximum (baseline vacuum) pressures across a feed for infants that were breastfeeding with and without a shield

considered covariates including CGA, current weight and shield use. Further, the variability of baseline $(p=$ $0.73)$, mean $(p=0.45)$ and peak $(p=0.38)$ vacuums were not significantly associated with milk intake.

Mean suck rates were $89 \pm 7$ sucks/min did not differ over the course of a feed $(p=0.47)$. Higher numbers of sucks per burst were associated with older infants (CGA; $p=0.008)$ and lower sucking rates $(\mathrm{p}<0.001)$ in that for each additional suck, the sucking rate is on average 0.6 s (95\% CI: 0.3, 0.9) slower. No overall associations were seen between sucking rate and baseline $(p=0.13)$ or peak $(p=0.09)$ vacuums, or with other considered covariates $(p=0.36)$.

Significant individual differences are seen for the associations between sucking rate and number of sucks in the burst $(\mathrm{p}<0.001)$, the baseline and peak vacuums $(\mathrm{p}<0.001$, both), and changes in sucking rate over the course of a feed $(\mathrm{p}<0.001)$.

Suck bursts of $>10$ sucks were present in $36 / 38$ of feeds. This pattern was more common than single sucks, with 9 infants having over a third of suck bursts consisting of more than 10 sucks. Median [IQR] frequency of bursts

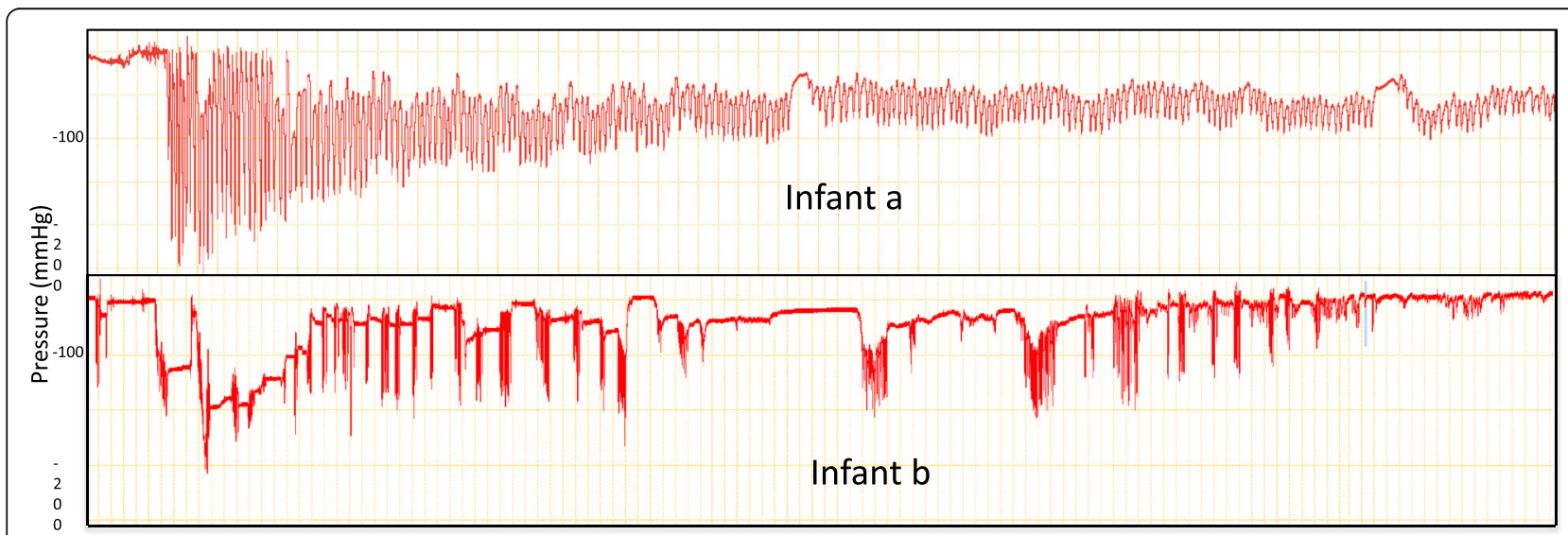

Fig. 5 Intra-oral vacuum traces of a breastfeed for 2 preterm infants (a) this infant displays peak vacuums between $-90 \mathrm{mmHg}$ and $-250 \mathrm{mmHg}$ and is able to maintain suck bursts with more than 10 sucks per burst (b) this infant applies peak vacuum between $-10 \mathrm{mmHg}$ and $-150 \mathrm{mmHg}$ and often has less than 10 sucks per suck burst and longer pauses than infant (a) 
$>10$ sucks was $8.5[0,45]$ and as a percentage of the number of suck bursts in the feed, on average $25 \% \pm 18 \%$. The median $[\mathrm{IQR}]$ number of single sucks was $5[3,9.5]$. The proportion single sucks bursts ranged from 0 to $38 \%$ with a median [IQR] of $11 \%$ [6.25\%, 17.5\%].

\section{Discussion}

Preterm infants are at risk of feeding difficulties due to the immaturity of their neurological and motor systems, which are magnified in those with underlying complications [53]. As delay in attainment of independent oral feeding may extend the time to discharge [54], a detailed and comprehensive knowledge of the physiology of feeding is essential to develop evidence-base guidelines and interventions that support the feeding maturation of the preterm infant and minimise long term behavioural eating disorders such as oral aversion $[55,56]$. In this study we found that stable preterm infants removed milk from the breast by lowering their tongue in a manner similar to the tongue action of term breastfeeding infants however the vacuum created by the preterm infant is weaker than the term infant. The only factors related to effectiveness of milk removal were; duration of the feed and the time spent actively sucking at the breast.

It is often presumed that the preterm infant lacks the ability to suck or has an inefficient suck [57], however we have shown that in preterm infants with no major complications employ a sucking mechanism during breastfeeding that is similar to that of the term infant (Table 3; Figs. 1 and 2). That is the preterm infant lowered its tongue away from the palate to generate vacuum, reaching a peak vacuum when the tongue was at its lowest point. During the downward motion of the tongue the soft palate moved downwards and remained in contact with the posterior tongue. Milk flowed into the cavity bounded by the tip of the nipple/nipple shield, hard palate, soft palate and ventral surface of the tongue. As the tongue moved upwards the vacuum reduced in strength and the milk was cleared from the oral cavity. No marked peristaltic action of the tongue was evident (Fig. 1). This suggests a mature sucking motion has developed in utero, consistent with reports of thumb sucking identified by real time ultrasound imaging in utero as early as 15-21 weeks [58]. Therefore, ineffective and inefficient feeding performance in preterm infants is likely to be due the inability to generate adequate vacuum strength and/or disorganized sucking due to poor suck-swallow-breathe co-ordination.

Optimal positioning of the nipple in relation to the hard-soft palate junction should be such that the infant is able to remove an appropriate volume of milk, that can be cleared to the pharyngeal area during the oral phase of swallowing [57]. Interestingly, positioning of the nipple was not different whether a nipple shield was used or not
(Table 3). And the N-HSPJ distance was comparable to that of term infants (TU: $6.5 \mathrm{~mm}$; TD $4.7 \mathrm{~mm}$ ) [45] despite the oral cavity of preterm infants being much smaller, indicating the existence of a possible 'sweet spot' where a bolus of milk can be accommodated, without triggering the gag reflex [59]. One might speculate that different sizes of shields could influence the positioning in the oral cavity, such that if it is too close to the HSPJ it may only allow a small bolus to be removed or may discouraging sucking. Alternatively, if the shield and nipple were located too distant from the HSPJ, the strength of vacuum applied might be reduced; resulting in a reduction in the amount of milk removed.

Movement of the nipple in the preterm oral cavity was similar to term infants overall (term: approx. $1.8 \mathrm{~mm} \mathrm{[45];}$ preterm: approx. $2.0 \mathrm{~mm}$; Table 3; Fig. 1) and the downward movement of the mid tongue was highly variable between infants (IOD: 1.9 to $8.8 \mathrm{~mm}$ ) and across the breastfeed (Fig. 3). Surprisingly, the average degree of IOD (Table 3) is similar to that of the term breastfeeding infant. Normally the tongue rests on the palate in the tongue up position, in term infants [45] however in 3 infants that was not the case. Two of the infants were fed with a shield, raising the possibility that the shield is too large and is restricting upward movement of the tongue. This would be similar to the issues encountered with women with large nipples where position of the nipple and tongue movement is likely impacted [60].

Nipple shields are often used to facilitate breastfeeding in preterm infants by enabling attachment to the breast and facilitating milk removal [61] however, there are conflicting reports as to whether they impact long term breastfeeding outcomes. A recent large cohort study found no relationship between nipple shield use and age at exclusive breastfeeding in one analysis [62] and an increased risk of not achieving exclusive breastfeeding (49\% exclusively feeding with nipple shield use and 66\% without) in another analysis [63]. It is not clear whether all factors known to influence exclusive breastfeeding were accounted for and frequency of use was not reported. A within infant study has shown that infants receive more milk from the breast when using nipple shields [61] therefore there is a clear need to understand how nipple shields function in the preterm infant. Better attachment to the breast was supported by the observation that baseline vacuum values of infants that fed with a shield were similar to the infants that were capable of feeding without a shield (Fig. 4). However, whilst we found that the preterm infants' pattern of tongue movement during breastfeeding is similar to term infants and is not altered with nipple shield use they generated a much weaker intra-oral vacuum (mean vacuum: $-40.6 \pm 27.8$ ) than term infants than term infants $(-114 \pm 50 \mathrm{mmHg})$. Since intra-oral vacuum is instrumental in milk removal 
from the breast and weak vacuum is associated with both poor milk intake and bottle-feeding efficiency [64] further research should focus on improving milk transfer rates during breastfeeding both with and without nipple shields. Factors that might influence milk transfer include the size of the nipple shield relative to the size of the nipple and infant's oral cavity and the volume of milk in the breast (or degree of breast fullness) as this influences milk flow rates in that milk flow rates are faster with greater degrees of fullness [65].

The delay that preterm infants experience in the attainment of feeding milestones has been partly attributed to the infant's inability to generate sufficient vacuum, as well as uncoordinated sucking, thereby reducing feed efficacy [64]. These factors are partly reflected in the large variability within and between infants, particularly across a breastfeed (Figs. 4 and 5). Most notably features differed to term infants; all suck burst vacuums (mean, baseline and peak) and pause vacuums reduced, across a breastfeed whereas baseline and pause vacuums strengthen across a breastfeed in term infants [66]. The reduction in vacuums across a feed is commensurate with clinical observations of the preterm infant tiring during the feed, relaxing its attachment to the breast/shield and becoming less effective at milk removal $[61,67]$.

Logically clinicians assume that as the infant grows and matures their ability to feed or create adequate feeding vacuums improves [64]. We did not find strength of vacuum to be related to either infant weight (birth-weight, weight at feed) or age (gestational age, corrected gestational age) casting doubt on the notion that larger, older infants are mature enough to create strong intra-oral vacuums compared to their younger, lighter counterparts [43]. These findings lend support to the practice of beginning feeding as soon as the infant achieves cardiorespiratory stability [68]. Certainly, according to Lau's bottlefeeding data, one would expect older infants to progress more rapidly, however lower vacuums are typically sufficient to remove milk from the bottle compared to the breast [39]. The inability to create and maintain a substantial level of vacuum during breastfeeding to remove adequate volumes of milk could result from issues other than immaturity such as respiratory issues [69], poor suck-swallow-breathe coordination [70], nipple shields and the behavioral state of the infant during the breastfeed. Indeed, further investigation of the influence of these factors on the success of breastfeeding is warranted particularly across time.

Sucking rates of the preterm infants $(89 \pm 7$ sucks/min) were similar to those documented for term breastfeeding infants [66, 71-73]. However, sucking rate was calculated excluding single sucks, which rarely occurs in term breastfeeding infants and may be another marker of maturation of infant feeding. Sucking rates remained relatively consistent over the course of the feed, whereas they increased across the breastfeed in term infants [66] and is speculated to be due to reduced milk flow rate, decreased availability of milk and infant satiety [66]. The lack of changes in the sucking rate in the preterm breastfeeding infant suggests an immature response to the breast, in that it may be difficult for the infant to suck consistently when milk is available during the milk ejection period [74]. Alternatively, low milk production and low volumes in the breast may reduce milk flow rate, thereby influencing preterm sucking patterns. It may also reflect an aspect of feed maturation, in that older infants tended to generate more sucks and suck more slowly during a breastfeed than the younger infants, however this was not associated with either baseline (latch) or peak vacuum suggesting that coordination of the suck swallow breathe process could also be impacting sucking rates.

Another suggested marker of developmental progress, based on observations of bottle-feeding, is the ability of infants to maintain 10 or more sucks for a suck burst, which reflects organized breathing $[75,76]$. In this study, all but 2 infants (5\%) exhibited at least one suck burst of 10 or more sucks, with on average only a quarter of the feed consisting of suck bursts $>10$ sucks. As mentioned previously, single sucks are rare in term breastfeeding infants compared to preterm infants and in this study single suck 'bursts' accounted for $11 \%$ of the feed (median; range: 0 to $38 \%$ ). Potentially a reduction of single sucks during breastfeeding could be indicative feeding progression. Further studies monitoring preterm breastfeeding characteristics over time are required to elucidate changes in vacuum patterns.

The volumes of milk removed from the breast by the preterm infants in this study were low and, in some cases much lower than the amount prescribed to ensure adequate growth. For example, $26 \%$ of the infants received no milk (3/38) or $<5 \mathrm{~mL}(7 / 38)$ and only one infant reached the prescribed volume. Whilst it is expected that stronger intra-oral vacuums during breastfeeding would result in increased milk intake, as demonstrated by Lau et al. [64] in preterm bottle-fed infants, we did not find this. Neither did we find a relationship between variability of vacuum strength and milk intake This maybe because preterm infants are required to suck more strongly at the breast and therefore fatigue more rapidly [67]. Thus improving milk transfer from the breast might require more emphasis on the breast and time spent actively sucking at the breast although the effect is small (average $0.07 \mathrm{~mL} / \mathrm{min}$ spent sucking).

\section{Conclusion}

Breastfeeding preterm infants generated intra-oral vacuum in the same manner as term infants albeit at a lower level. 
Intra-oral vacuum strengths were not associated with milk intake, rather the duration of the feed and the time spent actively sucking was related to milk volumes. Further research is required to elucidate factors that influence preterm infant milk intake during breastfeeding as well longitudinal studies to track maturation of breastfeeding skills.

\section{Abbreviations}

B: Baseline; CGA: Corrected gestation age; HMO: Human milk oligosaccharide: IOD: Intra-oral depth; M: Mean; NEC: Necrotizing enterocolitis; N-HSPJ: Nipple hard-soft palate junction; P: Peak; TD: Tongue down; TU: Tongue up

\section{Acknowledgements}

The authors would like to extend their sincere thanks to the families that participated in the study.

\section{Funding}

Medela AG did not sponsor the study and did not participate in study design, interpretation of results or writing of the manuscript.

\section{Availability of data and materials}

The datasets used and/or analysed during the current study are available from the corresponding author on reasonable request.

\section{Authors' contributions}

DG conceived the study, collected data, interpreted results and wrote the manuscript. AH cleaned the data, carried out statistical analysis, participated in interpretation of the results and editing of the manuscript. $\mathrm{HG}$ participated in interpretation of the results and writing of the manuscript. CK and KN assisted in study design, participant recruitment, data collection, data entry and editing of the manuscript. KS conceived the study, assisted in interpretation of the results and editing of the manuscript. All authors read and approved the final manuscript.

\section{Ethics approval}

Mothers supplied written, informed consent to participate in the study, which was approved by the Scientific Research Ethics Committee of King Edward Memorial Hospital. Mothers were part of a larger RCT:AustralianNewZealandClinicalTrialsRegistry, ACTRN12614000875606, http://www.ANZCTR.org.au/ACTRN12614000875606.aspx).

\section{Consent for publication}

Not applicable.

\section{Competing interests}

The DG has received an unrestricted research grant from Medela AG. AH and HG have received a salary from the unrestricted research grant. DG has received funding for lectures and attendance of conferences.

\section{Publisher's Note}

Springer Nature remains neutral with regard to jurisdictional claims in published maps and institutional affiliations.

\section{Author details \\ 'School of Molecular Sciences, Faculty of Science M310, The University of Western Australia, Perth, WA 6009, Australia. ${ }^{2}$ Centre for Neonatal Research and Education, King Edward Memorial Hospital, Perth, WA, Australia. ${ }^{3}$ School of Paediatrics and Child Health, The University of Western Australia, Perth WA, Australia.}

Received: 15 February 2017 Accepted: 6 November 2017

Published online: 17 November 2017

\section{References}

1. Ip S, Chung M, Raman G, Chew P, Magula N, DeVine D, Trikalinos T, Lau J. Breastfeeding and maternal and infant health outcomes in developed countries. Evid Rep Technol Assess (Full Rep). 2007;153:1-186.
2. Eidelman Al, Schanler RJ, Johnston M, Landers S, Noble L, Szucs K Viehmann L. Breastfeeding and the use of human milk. Pediatrics. 2012; 129(3):e827-41.

3. Schanler RJ. Outcomes of human milk-fed premature infants. Semin Perinatol. 2011;35(1):29-33.

4. Victora CG, Bahl R, Barros AJ, Franca GV, Horton S, Krasevec J, Murch S, Sankar MJ, Walker N, Rollins NC, et al. Breastfeeding in the 21st century: epidemiology, mechanisms, and lifelong effect. Lancet. 2016;387(10017):475-90.

5. Lechner BE, Vohr BR. Neurodevelopmental outcomes of preterm infants fed human milk: a systematic review. Clin Perinatol. 2017;44(1):69-83.

6. Lönnerdal B. Infant formula and infant nutrition: bioactive proteins of human milk and implications for composition of infant formulas. Am I Clin Nutr. 2014;99(3):712S-7S. doi:10.3945/ajcn.113.071993. Epub 2014 Jan 22.

7. Hamosh M. Bioactive factors in human milk. Pediatr Clin N Am. 2001;48(1):69-86.

8. Cong X, Judge M, Xu W, Diallo A, Janton S, Brownell EA, Maas K, Graf J. Influence of feeding type on gut microbiome development in hospitalized preterm infants. Nurs Res. 2017:66(2):123-33.

9. Gregory KE, Samuel BS, Houghteling P, Shan G, Ausubel FM, Sadreyev RI, Walker WA. Influence of maternal breast milk ingestion on acquisition of the intestinal microbiome in preterm infants. Microbiome. 2016;4(1):68.

10. Collado MC, Rautava S, Aakko J, Isolauri E, Salminen S. Human gut colonisation may be initiated in utero by distinct microbial communities in the placenta and amniotic fluid. Sci Rep. 2016:6:23129.

11. Autran CA, Kellman BP, Kim JH, Asztalos E, Blood AB, Spence EC, Patel AL, Hou J, Lewis NE, Bode L. Human milk oligosaccharide composition predicts risk of necrotising enterocolitis in preterm infants. Gut. 2017;

12. Underwood MA, Gaerlan S, De Leoz ML, Dimapasoc L, Kalanetra KM, Lemay DG, German JB, Mills DA, Lebrilla CB. Human milk oligosaccharides in premature infants: absorption, excretion, and influence on the intestinal microbiota. Pediatr Res. 2015;78(6):670-7.

13. McGuire W, Anthony M. Donor human milk versus formula for preventing necrotising enterocolitis in preterm infants: systematic review. Arch Dis Child Fetal Neonatal Ed. 2003;88(1):F11-4.

14. Schanler RJ, Lau C, Hurst NM, Smith EOB. Randomized trial of donor human milk versus preterm formula as substitutes for mothers' own milk in the feeding of extremely premature infants. Pediatrics. 2005;116(2):400-6.

15. Bravi F, Wiens F, Decarli A, Dal Pont A, Agostoni C, Ferraroni M. Impact of maternal nutrition on breast-milk composition: a systematic review. Am J Clin Nutr. 2016;104(3):646-62.

16. Lee S, Kelleher SL. Biological underpinnings of breastfeeding challenges: the role of genetics, diet, and environment on lactation physiology. Am J Phys Endocrinol Metab. 2016:311(2):E405-22.

17. Asztalos EV, Campbell-Yeo M, da Silva OP, Ito S, Kiss A, Knoppert D, Group ESC. Enhancing human milk production with Domperidone in mothers of preterm infants. J Hum Lact. 2017:33(1):181-7.

18. Dos Santos CO, Dolzhenko E, Hodges E, Smith AD, Hannon GJ. An epigenetic memory of pregnancy in the mouse mammary gland. Cell Rep. 2015;11(7):1102-9.

19. Lawal AM, Idemudia ES. Examining maternal age, breastfeeding self-efficacy and health locus of control in psychological wellbeing of mothers. Psychol Health Med. 2017:1-9.

20. McAndrew F, Thompson J, Fellows L, Large A, Speed M, Renfrew MJ. Infant feeding survey 2010. Leeds: Health and Social Care Information Centre; 2012.

21. Dennis CL, Gagnon A, Van Hulst A, Dougherty G, Wahoush O. Prediction of duration of breastfeeding among migrant and Canadian-born women: results from a multi-center study. J Pediatr. 2013:162(1):72-9.

22. Bentley M, Gavin L, Black MM, Teti L. Infant feeding practices of low-income, African-American, adolescent mothers: an ecological, multigenerational perspective. Soc Sci Med. 1999;49(8):1085-100.

23. Callen J, Pinelli J. A review of the literature examining the benefits and challenges, incidence and duration, and barriers to breastfeeding in preterm infants. Adv Neonatal Care. 2005;5(2):72-88.

24. Meier PP, Engstrom JL. Evidence-based practices to promote exclusive feeding of human milk in very low-birthweight infants. NeoReviews. 2007;8(11):e467-77.

25. Saint L, Smith M, Hartmann PE. The yield and nutrient content of Colostrum and milk of women from giving birth to 1 month post-partum. Br J Nutr. 1984:52(1):87-95.

26. Cregan MD, De Mello TR, Kershaw D, McDougall K, Hartmann PE. Initiation of lactation in women after preterm delivery. Acta Obstet Gynecol Scand. 2002:81(9):870-7.

27. Parker LA, Sullivan S, Krueger C, Mueller M. Association of timing of initiation of breastmilk expression on milk volume and timing of 
lactogenesis stage II among mothers of very low-birth-weight infants. Breastfeed Med. 2015;10(2):84-91.

28. Hill PD, Aldag JC, Chatterton RT, Zinaman M. Primary and secondary mediators' influence on milk output in lactating mothers of preterm and term infants. J Hum Lact. 2005;21 (2):138-50.

29. Hill PD, Aldag JC, Chatterton RT. Initiation and frequency of pumping and milk production in mothers of non-nursing preterm infants. J Hum Lact. 2001;17(1):9-13.

30. Winberg J. Mother and newborn baby: mutual regulation of physiology and behavior- a selective review. Dev Psychiatry. 2005;47:217-9.

31. Kent JC. How breastfeeding works. J Midwifery Womens Health. 2007;52(6): 564-70.

32. Kent JC, Mitoulas LR, Cregan MD, Ramsay DT, Doherty DA, Hartmann PE. Volume and frequency of breastfeedings and fat content of breast milk throughout the day. Pediatrics. 2006;117(3):e387-95.

33. Hill PD, Aldag JC, Chatterton RT. Effects of pumping style on milk production in mothers of non-nursing preterm infants. J Hum Lact. 1999; 15(3):209-16.

34. Hill PD, Aldag JC, Chatterton RT, Zinaman M. Comparison of milk output between mothers of preterm and term infants: the first 6 weeks after birth. J Human Lact. 2005;21:22-30.

35. Kent JC, Mitoulas LR, Cregan MD, Geddes DT, Larsson M, Doherty DA, Hartmann PE. Importance of vacuum for breastmilk expression. Breastfeed Med. 2008;3(1):11-9.

36. Geddes DT, Kent JC, Mitoulas LR, Hartmann PE. Tongue movement and intra-oral vacuum in breastfeeding infants. Early Hum Dev. 2008;84(7):471-7.

37. Geddes DT, Sakalidis VS, Hepworth AR, McClellan HL, Kent JC, Lai CT, Hartmann PE. Tongue movement and intra-oral vacuum of term infants during breastfeeding and feeding from an experimental teat that released milk under vacuum only. Early Hum Dev. 2012;88(6):443-9.

38. Lau C. Oral feeding in the preterm infant. NeoReviews. 2006;7(1):e19-27.

39. Lau C, Alagugurusamy R, Schanler R, Smith E, Shulman R. Characterization of the developmental stages of sucking in preterm infants during bottle feeding. Acta Paediatr. 2000;89(7):846-52.

40. Lau C, Smith E, Schanler R. Coordination of suck-swallow and swallow respiration in preterm infants. Acta Paediatr. 2003:92(6):721-7.

41. Barlow SM. Oral and respiratory control for preterm feeding. Curr Opin Otolaryngol Head Neck Surg. 2009;17(3):179.

42. Amaizu N, Shulman R, Schanler R, Lau C. Maturation of oral feeding skills in preterm infants. Acta Paediatr. 2008:97(1):61-7.

43. Mathew OP, Bhatia J. Sucking and breathing patterns during breast-and bottle-feeding in term neonates: effects of nutrient delivery and composition. Am J Dis Child. 1989;143(5):588-92.

44. Elad D, Kozlovsky P, Blum O, Laine AF, Po MJ, Botzer E, Dollberg S, Zelicovich M, Ben Sira L. Biomechanics of milk extraction during breast-feeding. Proc Natl Acad Sci U S A. 2014;111(14):5230-5.

45. McClellan HL, Sakalidis VS, Hepworth AR, Hartmann PE, Geddes DT. Validation of nipple diameter and tongue movement measurements with B-mode ultrasound during breastfeeding. Ultrasound Med Biol. 2010;36(11):1797-807.

46. Sakalidis VS, Williams TM, Garbin CP, Hepworth AR, Hartmann PE, Paech MJ, Geddes DT. Ultrasound imaging of infant sucking dynamics during the establishment of lactation. J Hum Lact. 2013;29(2):205-13.

47. Weber F, Woolridge M, Baum J. An ultrasonographic study of the organisation of sucking and swallowing by newborn infants. Dev Med Child Neurol. 1986;28(1):19-24.

48. Ardran G, Kemp F. A correlation between suckling pressures and the movements of the tongue. Acta Paediatr. 1959;48(3):261-72.

49. Prieto C, Cárdenas H, Salvatierra A, Boza C, Montes C, Croxatto H. Sucking pressure and its relationship to milk transfer during breastfeeding in humans. J Reprod Fertil. 1996;108(1):69-74.

50. R Core Team R. R: a language and environment for statistical computing. Vienna: Foundation for Statistical Computing; 2014.

51. Pinheiro J, Bates D, DebRoy S, Sarkar D. Linear and nonlinear mixed effects models. R package version. 2007;3:57.

52. Sarkar D. Lattice: multivariate data visualization with R: Springer Science \& Business Media. Edition 1. New York: Springer-Verlag; 2008 .

53. Bagnall A. Feeding problems. In: Jones E, King C, editors. Feeding and nutrition in the preterm infant. Edinburgh: Elsevier Health Sciences; 2005. p. 165-83.

54. Bertoncelli N, Cuomo G, Cattani S, Mazzi C, Pugliese M, Coccolini E, Zagni P, Mordini B, Ferrari F. Oral feeding competences of healthy preterm infants: a review. Int J Pediatr. 2012;2012
55. Douglas J, Bryon M. Interview data on severe behavioural eating difficulties in young children. Arch Dis Child. 1996;75(4):304-8.

56. Burklow KA, McGrath AM, Valerius KS, Rudolph C. Relationship between feeding difficulties, medical complexity, and gestational age. Nutr Clin Pract. 2002;17(6):373-8.

57. Arvedson JC. Assessment of pediatric dysphagia and feeding disorders: clinical and instrumental approaches. Dev Disabil Res Rev. 2008;14(2):118-27.

58. Hepper PG, Shahidullah S, White R. Handedness in the human fetus. Neuropsychologia. 1991;29(11):1107-11.

59. Delaney A, Arvedson JC. Development of swallowing and feeding: prenatal through first year of life. Dev Disabil Res Rev. 2008;14:105-17.

60. Wison-Clay B, Hoover K. The breastfeeding atlas. 4th ed. Texas: LactNews Press; 2008

61. Meier PP, Brown LP, Hurst NM, Spatz DL, Engstrom JL, Borucki LC, Krouse AM. Nipple shields for preterm infants: effect on milk transfer and duration of breastfeeding. J Hum Lact. 2000;16(2):106-14. quiz 129-131

62. Maastrup R, Hansen BM, Kronborg H, Bojesen SN, Hallum K, Frandsen A, Kyhnaeb A, Svarer I, Hallstrom I. Breastfeeding progression in preterm infants is influenced by factors in infants, mothers and clinical practice: the results of a national cohort study with high breastfeeding initiation rates. PLoS One. 2014;9(9):e108208.

63. Maastrup R, Hansen BM, Kronborg H, Bojesen SN, Hallum K, Frandsen A, Kyhnaeb A, Svarer I, Hallstrom I. Factors associated with exclusive breastfeeding of preterm infants. Results from a prospective national cohort study. PLoS One. 2014;9(2):e89077.

64. Lau C, Sheena HR, Shulman RJ, Schanler RJ. Oral feeding in low birth weight infants. J Pediatr. 1997;130(4):561-9.

65. Ramsay DT, Mitoulas LR, Kent JC, Cregan MD, Doherty DA, Larsson M, Hartmann PE. Milk flow rates can be used to identify and investigate milk ejection in women expressing breast milk using an electric breast pump. Breastfeed Med. 2006;1(1):14-23.

66. Sakalidis VS, Kent JC, Garbin CP, Hepworth AR, Hartmann PE, Geddes DT. Longitudinal changes in suck-swallow-breathe, oxygen saturation, and heart rate patterns in term breastfeeding infants. J Hum Lact. 2013;29(2):236-45.

67. Garber J. Oral-motor function and feeding intervention. Phys Occup Ther Pediatr. 2013;33(1):111-38.

68. Nyqvist KH, Sjoden PO, Ewald U. The development of preterm infants' breastfeeding behavior. Early Hum Dev. 1999;55(3):247-64.

69. Mizuno K, Nishida Y, Taki M, Hibino S, Murase M, Sakurai M, Itabashi K. Infants with bronchopulmonary dysplasia suckle with weak pressures to maintain breathing during feeding. Pediatrics. 2007;120(4):e1035-42.

70. Mizuno K, Ueda A. The maturation and coordination of sucking, swallowing, and respiration in preterm infants. J Pediatr. 2003;142(1):36-40.

71. Cannon AM, Sakalidis VS, Lai CT, Perrella SL, Geddes DT. Vacuum characteristics of the sucking cycle and relationships with milk removal from the breast in term infants. Early Hum Dev. 2016;96:1-6.

72. McClellan H, Geddes D, Kent J, Garbin C, Mitoulas L, Hartmann P. Infants of mothers with persistent nipple pain exert strong sucking vacuums. Acta Paediatr. 2008;97(9):1205-9.

73. Sakalidis VS, McClellan HL, Hepworth AR, Kent JC, Lai CT, Hartmann PE, Geddes DT. Oxygen saturation and suck-swallow-breathe coordination of term infants during breastfeeding and feeding from a teat releasing milk only with vacuum. Int J Pediatr. 2012;2012:130769.

74. Ramsay DT, Kent JC, Owens RA, Hartmann PE. Ultrasound imaging of milk ejection in the breast of lactating women. Pediatrics. 2004;113(2):361-7.

75. Palmer MM. Identification and management of the transitional suck pattern in premature infants. J Perinat Neonatal Nurs. 1993;7(1):66-75.

76. Gewolb IH, Vice FL, Schwietzer-Kenney EL, Taciak VL, Bosma JF. Developmental patterns of rhythmic suck and swallow in preterm infants. Dev Med Child Neurol. 2001;43(1):22-7. 